\title{
What do children with cancer know about their medications?
}

\author{
Tamara MACDONALD, Derek MACDONALD, Bruce CROOKS, Cherie COLLICOTT. \\ Received (first version): 10-Mar-2011 \\ Accepted: 17-Sep-2011
}

\begin{abstract}
${ }^{*}$
Objectives: To explore the health literacy of children diagnosed with Acute Lymphoblastic Leukemia (ALL) through their knowledge of their medications.

Methods: Within the Basic Interpretive approach to qualitative research, semi-structured interviews were conducted with children from ages 6 to18 years $(n=16)$ between May and September 2009 to determine their knowledge of medication properties, medication habits and medication teaching. REB approval was obtained.

Results: The younger children (mean age 7.5 years) correctly answered, on average, $51 \%$ of the questions on colour, $26 \%$ of the questions on name, $25 \%$ of the questions on frequency, and $8 \%$ of the questions on the purposes of their medications. The older children (mean age 16 years) scored at least $35 \%$ higher for each characteristic. All of the younger children reported that physicians consistently directed medication education to parents only, and that the younger children were rarely present during these sessions. 13 of the 16 children stated that they want to learn more about and be more involved in education sessions addressing their medications.

Conclusion: Children with ALL at the IWK Health Centre do not have a good knowledge of their medications, however most children expressed that they want to know more about their medications.
\end{abstract}

Keywords: Health Literacy. Health Knowledge, Attitudes, Practice. Neoplasms. Child. Adolescent. Canada.

\section{QUE SABEN LOS NIÑOS CON CÁNCER SOBRE SUS MEDICACIONES?}

\section{RESUMEN}

Objetivos: Explorar la alfabetización en salud de los niños diagnosticados de leucemia linfoblástica aguda (LLA) a través de su conocimiento sobre la medicación.

Métodos: Con un abordaje de Interpretación Básico de investigación cualitativa, se realizaron entrevistas semi-estructuradas a niños de 6 a 18 años $(n=16)$ entre mayo y septiembre de 2009 para determinar su conocimiento de las propiedades de la medicación, costumbres de medicación y enseñanzas de la medicación. Se obtuvo aprobación de la Comisión de Ética.

Resultados: Los niños más jóvenes (edad media 7,5 años) respondían correctamente a una media de $51 \%$ de las preguntas sobre color, $26 \%$ de las preguntas sobre el nombre, $25 \%$ de las preguntas sobre frecuencia, y $8 \%$ de las preguntas sobre objetivos de la medicación. Los niños mayores (edad media 16 años) puntuaron al menos en el $35 \%$ para cada característica. Todos los niños más jóvenes informaron que normalmente el medico realizada la educación sobre la medicación a sus padres solamente, y que los más jóvenes raramente estaban en esas sesiones. 13 de los 16 niños afirmaron que querían aprender más sobre la medicación y estar más involucrados en las sesiones educativas realizadas sobre su medicación. Conclusión: Los niños con LLA en el IWK Health Centre no tienen un buen conocimiento de sus medicaciones, sin embargo, la mayoría de los niños expresó que deseaban saber más sobre sus medicaciones.

Palabras clave: Alfabetización en Salud. Conocimientos, Actitudes y Práctica en Salud. Neoplasias. Niño. Adolescente. Canadá.

\section{INTRODUCTION}

\footnotetext{
*Tamara MACDONALD. Pharm D. Clinical Pharmacy Specialist, IWK/Dalhousie University. Halifax, Nova Scotia (Canada).

Derek MACDONALD. PhD Candidate. University of Georgia. Athens, GA (United States). Bruce CROOKS. MB, ChB. Oncology/Haematology, IWK/Dalhousie University. Halifax, Nova Scotia (Canada). Cherie COLLICOTT. Medical student. Dalhousie University. Halifax, Nova Scotia (Canada).
}

\begin{abstract}
Anecdotal evidence suggests that children with cancer do not have a good knowledge of their medications, based on children's inability to describe their medications on repeated visits. Lack of medication knowledge or low health literacy raises questions of the resulting effects on the potential success of treatment., ${ }^{1,2}$ The purpose of this study was to better understand what children with leukemia between the ages of 6 and 18 at the Izaak Walton Killam (IWK) Health Centre in Halifax, Nova Scotia know about their medications. The research questions include:
\end{abstract}


1. What do children with cancer know about concrete properties (name, size and shape, colour) of their medications.

2. What do children with cancer know about abstract properties (reason for taking, how they work, how they make you feel) of their medications.

\section{Medication knowledge}

For this study, medication knowledge was defined as the child's ability to answer the following questions: What are your medications? (i.e., names and physical properties); How are you supposed to take them? (e.g. once daily, on full stomach...); How do your medications work? (e.g. they ease pain, they kill cancer cells, they help with nausea...); Why do you need to take them?; How do your medications make you feel? (e.g. nauseated, drowsy...).

We based the cognitive level of the children in this study on Piaget stages of development. We chose an age range of 6-18 years (school aged children through to adolescence) We divided the children into 2 groups: those less than 12 years into Piaget's concrete operations stage (7- 12 years) and these children are refered to as the younger children throughout the study. Children 12 years and older fell into Piaget's formal operations stage where children are able to think more abstractly and more equipped to answer questions such as "How do your medications work in your body". These children are referred to as the older children in this study.

Piaget has proposed four stages of development: 1) The sensorimotor stage (not considered in this study as this stage describes $0-2$ year olds); 2) The preoperational stage (2- 7 years); 3) The concrete operations stage ( 7 to 12 years); and 4 ) The formal operations stage (12 years and older).We did also include 6 year olds who fall into the intuitive stage of Piaget's preoperational stage of development. It was felt that the 6 year olds would be able to answer the medication question in a similar way to the children who fall into the concrete operations stage ( 7 to 12 years). ${ }^{3}$

\section{Health literacy and medication knowledge}

Health literacy is the theoretical framework of this study and is used to help answer the research questions. Health literacy should be distinguished from general literacy, which refers to a person's ability to read and write. Health literacy is defined as "The degree to which individuals have the capacity to obtain, process, and understand basic health information and services needed to make appropriate health decisions". ${ }^{4}$ An individual's ability to obtain, process and understand information is linked to the difficulty of the information presented their culture of health beliefs and the quality of patient-provider communication. Low health literacy may be a result of inadequate communication and dedication from the healthcare team in providing appropriate and effective health information to patients and less due to limited literacy skills. ${ }^{5}$

Wolf et al. ${ }^{6}$ suggest analyzing health literacy as a cognitive skill set that includes processing speed, working memory, long-term memory, reasoning, and attention, as well as literacy and numeracy. Borzekowski ${ }^{7}$ builds upon theperspectives of Freire, Piaget, and Vygotsky to bring the concepts of scaffolding knowledge and empowerment as children grow. What complicates pediatric health literacy is that the parent's health literacy must be considered as well as the children's health literacy. ${ }^{8}$ The literature is inconsistent in reports of whether health literacy of the parent is a determinant of the health literacy of the child and the impact on health outcomes. ${ }^{5}$ Moreover, children within the same age group demonstrate variations in their ability to engage in self-care and their level of health literacy. Parents of children with chronic medical needs often transfer self-care responsibilities when their child is between the ages of 11 and 15 years. ${ }^{9}$ Transition to self-care, especially for children with special health care needs, includes developing the capacity to advocate on behalf of one-self or one's child, seeking health information and care, eliciting teachback, asking clarifying questions, and navigating the health system. Healthcare professionals should shift from their traditional focus on teaching what they think the patient needs, to identifying the needs of the patient and focusing on the teach-back method where the patients describe verbally back to the health professional what they have learned. ${ }^{8}$

\section{Medication teaching and empowerment}

There is a gap in the literature and in practice on how much information healthcare professionals should give to children undergoing treatment regardless of illness. Healthcare professionals should explain to both the child and parent that the child's participation is important. By participating in their medical visits children learn that they are important, increasing their self- confidence and giving them a sense of control of their own life. ${ }^{10}$ Encouraging the child to participate during medical visits may force healthcare professionals, and parents, and children to question their roles and become more aware of their responsibilities and obligations. $^{10}$

Giving information to children in a way that is tailored to their needs and not the needs of the parent has been shown to improve information retention. Happier and more informed patients tend to have improved health outcomes. From as young as 6 years, children want more involvement in discussions about their illness and an opportunity to have a say about their treatment. They would like information to be given in a way which they can understand. ${ }^{11}$ Making a decision on treatment with a child/adolescent and parent in a collaborative way will increase family satisfaction and compliance with treatment. ${ }^{11}$ Suffering from a disorder with an unpredictable outcome such as cancer influences interaction in a medical situation and affects patient compliance. ${ }^{12}$ In a review of childhood leukemia, some children readily complied with therapy while others rebelled against their parents. ${ }^{13}$ Adolescent patients who have regular and frequent conversations with health professionals about their diagnosis and uncertain future are more likely to cooperate with treatment. ${ }^{14}$ 
Children's participation in their own healthcare continues to be low, even though pediatricians believe that children should take an active part and be involved in decisions about their own health care. This includes children with life-threatening diseases such as cancer. Wassmer ${ }^{15}$ has shown the higher health-promoting value of active childparticipation. Although younger children seem less likely to contribute to the conversation due to a lack of conversational skills and cognitive understanding of their illness, it should not be assumed that their psychological and emotional needs are less than older children. ${ }^{15}$ Physicians rely more on children for obtaining information yet provide feedback primarily to parents. ${ }^{16}$ Pantell $^{16}$ describes one 8 -year-old child who provided her physician with information about the name, dosage, and schedule of her current medication because her father was unable to answer the physician's questions. It is important to consider the potential impact of what not including children might have on a child's ability to assume responsibility for his/her own medical care.

\section{METHODS}

Participants: 16 participants, between the ages of 6 and 18 years were recruited for this study. All participants had been diagnosed with acute lymphoblastic leukemia and were no less than one month into the maintenance phase of their treatment (thereby having similar medication profiles). Only English-speaking children were invited to participate as that was the language used by the interviewers.

Consent: Written Informed Consent was obtained from the participants or the parents/guardians of these children. In addition, Informed Consent was obtained from those children wanting to consent themselves. Any children wanting to assent were given an assent form to sign if they wished. This provided the opportunity for these children to be active in the consent process as there is no legal age of consent in Nova Scotia.

Methodology: According to Merriam ${ }^{17}$, all qualitative research includes the following. 1) the researcher's task is "to understand the meaning people have constructed about their world and their experiences" (p. 4). 2) The research is the primary instrument of data collection and analysis, which, Merriam goes on to say, is the ideal instrument because "the human instrument ... is able to be immediately responsive and adaptive" (p. 5). 3) Qualitative research is inductive. In other words, the qualitative research process is a journey from the specific (data) to the general (results). 4) "The product of a qualitative inquiry is richly descriptive" (p. 5). There are many approaches to qualitative research, but they all share these characteristics.

Based upon these common characteristics of all qualitative research comes the Basic Interpretive Qualitative Study, which is "probably the most common form of qualitative research" (p. 38). Merriam goes on to state that the purpose of the Basic Interpretive Qualitative Study is to "understand how people make sense of their lives and their experiences" (p. 38).

Data Collection: All semi-structured interviews took place at the IWK and lasted approximately 45-60 minutes. All participants were asked a series of questions sometimes followed by probes, about their medication knowledge. The answers were recorded verbatim using a redundant Dictaphone audio recording system.

Data Analysis: The medication knowledge data that resulted from the qualitative interviews were entered into the Atlas Ti data management tool. Data were analysed using the constant comparative method, which is a technique used to generate grounded theory. Grounded theory is a theory created without the use of a priori assumptions of how the data informs the research questions. ${ }^{18,19}$ Using this technique, data are examined, broken down, compared, categorized, and re-assembled repetitively. Data are repeatedly grouped based on the principles of coherency (data that are logically connected) and consistency (data that indicate similar meaning). This process continues and the concepts are further developed and refined until a "strong theoretical understanding" has emerged. ${ }^{18}$

Medication knowledge data were based on response data the children gave 4 to 5 medications (Septra, Methotrexate, Mercaptopurine, Chlorhexidine, Steroids) that all the children were required to take on a daily basis as part of their treatment for leukemia. For each property (name, colour, frequency, time, purpose, mechanism) we collapsed the data across all participants and then determined accuracy rates between what they assumed and what was correct. The accuracy rate was taken as the total number correct divided by the total number. All participants were also asked a few questions regarding who educates them about their medications and what helps them learn in order to gain an understanding of how involved they are with their medication teaching.

\section{RESULTS}

Overall children of all ages had limited knowledge of their medications (Table 1) with the younger children having less understanding. On average the children were accurate on: description of colours $61 \%$ of the time; time they should take the medications $53 \%$ of the time; names $45 \%$ of the time, purposes $27 \%$ of the time, and how their medications work in their bodies $0 \%$ of the time. We found that more than $73 \%$ of children reported that physicians directed medication education to only the parents and that $64 \%$ of children are only sometimes or never present in the room. The younger children did not score as well as the older children even on the simple concrete questions regarding colour and name of their medications. A number of these children had been taking these medications for over a year and would have been expected to answer these questions based on Piaget's stages of development. The reason for this lack of retention may be due to the child's lower health literacy or to the lack of effective 


\begin{tabular}{|c|c|c|c|}
\hline & $\begin{array}{c}\text { Total } \\
\text { (older + younger) }\end{array}$ & $\begin{array}{l}\text { Older Group ( } \geq 12 \text { yo }) \\
\text { mean }=16.06 \text { yrs }\end{array}$ & $\begin{array}{l}\text { Younger Group }(<12 \text { yo }) \\
\text { mean }=7.70 \text { yrs }\end{array}$ \\
\hline Drug Name * & $33 / 74(44.59 \%)$ & $19 / 21(90.5 \%)$ & $14 / 53(26.4 \%)$ \\
\hline Colour * & $45 / 74(60.81 \%)$ & $18 / 21(85.7 \%)$ & $27 / 53(50.9 \%)$ \\
\hline Frequency * & $27 / 74(36.48 \%)$ & $14 / 21(66.6 \%)$ & $13 / 53(24.5 \%)$ \\
\hline Time * & $39 / 74(52.70 \%)$ & $18 / 21(85.7 \%)$ & $27 / 53(50.9 \%)$ \\
\hline Purpose * & $20 / 74(27.02 \%)$ & $16 / 21(76.2 \%)$ & $4 / 53(7.5 \%)$ \\
\hline Mechanism * & $0 / 74 \quad(0.00 \%)$ & $0 / 21 \quad(0.0 \%)$ & $0 / 53(0.0 \%)$ \\
\hline Parents responsible for meds ** & $8 / 12(66.70 \%)$ & $0 / 4 \quad(0.0 \%)$ & $8 / 8(100 \%)$ \\
\hline Child Solely responsible for Meds ** & $3 / 12(25.00 \%)$ & $3 / 4(75.0 \%)$ & $0 / 8(0.0 \%)$ \\
\hline Parent and Child share responsibility for meds ** & $1 / 12(8.30 \%)$ & $1 / 4(25.0 \%)$ & $0 / 8 \quad(0.0 \%)$ \\
\hline Want to be involved? Learn More? ${ }^{* *}$ & $10 / 12(83.3 \%)$ & $3 / 4(75.0 \%)$ & $7 / 8(87.5 \%)$ \\
\hline Doc talks to Parent? ${ }^{* *}$ & $8 / 11(72.7 \%)$ & $1 / 4(25.0 \%)$ & $7 / 7(100 \%)$ \\
\hline Doc talks to Parent and Child ${ }^{* \star}$ & $3 / 11(27.3 \%)$ & $3 / 4(75.0 \%)$ & $0 / 7 \quad(0.0 \%)$ \\
\hline Child Always present for Teaching ** & $4 / 11(36.4 \%)$ & $3 / 4(75.0 \%)$ & $1 / 7(14.3 \%)$ \\
\hline Child Never Present for Teaching ** & $5 / 11(45.4 \%)$ & $1 / 4(25.0 \%)$ & $4 / 7(57.1 \%)$ \\
\hline Child sometimes Present for Teaching ${ }^{\star *}$ & $2 / 11(18.2 \%)$ & $0 / 4(0.0 \%)$ & $2 / 7(28.6 \%)$ \\
\hline Forgot To Take a Medicine ${ }^{* *}$ & $10 / 12(83.3 \%)$ & $4 / 4(100 \%)$ & $6 / 8(75.0 \%)$ \\
\hline \multicolumn{4}{|c|}{$\begin{array}{l}{ }^{*} \text { Total score: } 16 \text { children } \times 4-5 \text { medications each }=74 \\
{ }^{* *} \text { Total score is number of children (we were not able to ask all children each question) }\end{array}$} \\
\hline
\end{tabular}

communication and teaching provided from the health professionals. All children, but especially younger children, may not be receiving adequate and effective medication education and as a consequence may not have a good knowledge of their medications. Interestingly, $81 \%$ of children in all age groups stated that they would want to be involved and are eager to learn more about their medications.

\section{DISCUSSION}

The results of this study show that children of all ages have limited knowledge of their medications. Children 12 years and older appear to have a better knowledge of the characteristics of their medications but still do not appear to know how their medications work. Consistent with Piaget the older children do have the ability to think abstractly and thus have the potential to understand what happens to a medication once it is taken into the body. The older children were not able to describe how their medications work. This is may be due to the fact that they have not been effectively taught this concept. This may have also occurred due to the small sample size, it may be that with a larger sample older children would have been captured that could describe simple mechanisms of action of their medications. It was expected that the older children have little problem answering the simple questions of the name, colour and how many times a day to take the medications, yet they showed difficulty even with these simple questions. It appears that there is a clear gap in medication knowledge for all children but it is with the younger children that this gap is the largest. This is critical because children with low health literacy may have worse health outcomes. ${ }^{9}$ It should be noted that due to the small sample size it may be difficult to determine the true knowledge of each age group based on Piaget's cognitive developmental stages. However since children of all ages in this study did not appear to have a good knowledge of their medications the authors of this study do feel that investigation into the teaching practices of the healthcare professionals involved is warranted.
All of the younger children reported that their parents are entirely responsible for their medications. It has been suggested that parents become comfortable with the transition of self-care to a child between the ages of 11 to 15 years. This does not mean that children younger than this cannot be involved with simple decisions around their medications for example, what time of the day to take their medications. Piaget describes the concrete operations stage of intellectual development from 7 to 12 years. In this stage most children are capable of more logical thought in the sense that they can understand that they have cancer and that the medications help them to get better, they should also be able to start to understand specifics about their medications.

Once the healthcare professional has determined the cognitive level of the child (by asking open ended questions), they should communicate with the child at that level. Some children are able to communicate at a very young age ( 3 or 4 years) and most children by the age of 7 or 8 years, can actively participate during medical encounters with health care professionals. In order to facilitate communication with children healthcare professionals should use open-ended questions to assess what the child understands. Ask the child if he or she has any questions and use written communication. Nonverbal communication (gestures, hugs, tone of voice) is also important when communicating with children. Healthcare professionals need to sit at the same height as the child and be aware of their facial expressions, tone of voice, and gestures. ${ }^{19}$

Toddlers and preschool children may not be capable of learning about medications to the same extent as older children, but it is important to include them in medicine education that pertains to them. The more the child is included the more he or she will feel that their medications are important. ${ }^{19}$

School age children can become actively involved in learning about their medications. It should be understood that large variation exists among children in cognitive levels, and in their experiences with medications. Open-ended questions such as 
"why do you need to take this medicine?" and "How does the medicine work?" can help the healthcare professional assess whether the child is starting to understand cause and effect relationships and that internal physiological mechanisms contribute to illness. This typically happens around 7 years of age, but it can happen when younger or older. Asking the parent questions can help in determining how independent the child is becoming in taking medications. $^{19}$

Healthcare professionals can give children more autonomy by telling them to work with their mother or father in taking the drug instead of simply warning them not to take it unless one of those people are present. Another strategy, which fosters compliance and builds autonomy, is to give a child a calendar that can be marked when a dose is taken. $^{19}$

Empowerment is a component of health literacy. ${ }^{8} \mathrm{~A}$ lack of autonomy and empowerment is a possible contributor to the younger children's lower observed health literacy. Perhaps it is that health care professionals, such as physicians, pharmacists and nurses are not enabling and encouraging children to learn. Adult patients are enabled to have autonomy with their own health care. However pediatric patients pose a unique problem because pediatric patients have parents that take care of them, Often healthcare professionals may see the parents as being responsible for consent, and by default may neglect to involve the young patients. The younger children said that the doctors only speak to the parents when educating about new medications, $86 \%$ of the younger children said they were never or only sometimes present in the room while their parents and healthcare professionals were speaking about their medications. Empowerment during treatment is a key factor, especially for the pediatric population who can become forgotten when we also must strive to teach parents about medicines as well. 13 of the 16 children in this study stated that they want to know more about their medications and they want to be more involved.

We found that $83 \%$ of children admitted to forgetting one or more medications during their treatment for leukemia all with parental supervision. Perhaps with more empowerment children may feel more responsible and more likely to remember to take their medications even when their parents forget.
Also, we found that none of the children knew how their medications work inside their bodies. This is important because some of the adolescents in our study stated that if they knew more about their medications then they may be more willing to take their medications as prescribed.

Work has already begun in response to the findings of this study. Now that we know there are clear gaps in children's knowledge about their medications we are striving to provide a model of consistent medication information. The desirable model will focus on keeping the content developmentally appropriate, comprehensive, and help to shift pedagogical methods from a disciplinespecific approach to a patient-focused approach. We want to develop a model that would focus on building empowerment. Children need to become active participants in their health care. We should also have guidelines for health care professionals on how they can help empower pediatric patients with their medications.

\section{CONCLUSIONS}

The children that were interviewed in this study did not have a good knowledge of their medications, with younger children knowing less than the older children. The younger children were regularly not spoken to directly about their medications by their healthcare team and were normally not given any responsibility by their parents in regards to their medications.

Healthcare professionals and parents need to involve children of all ages with life-threatening illnesses like cancer in their medication education. They need to promote increased health literacy and enable children to become rational medication users.

\section{CONFLICT OF INTEREST}

None declared.

This study has been supported by the Dalhousie Pharmacy Endowment Fund and the Norah Stephens Oncology Scholars' Award.

\section{References}

1. Bandura A. Social learning theory. Englewood Cliffs (NJ): Prentice Hall, 1976.

2. Slavin LA, O'Malley JE, Koocher GP, Goster DJ. Communication of the cancer diagnosis to pediatric patients: impact on long-term adjustment. Am J Psych. 1982;139:179-83.

3.Piaget J. The moral judgment of the child. New York: Harcourt, Brace \& World; 1932.

4.Institute of Medicine. Health Literacy: A prescription to End Confusion. Washington, DC: National Academies Press; 2004.

5. Hironaka LK, Paasche-Orlow MK. The implications of health literacy on patient-provider communication. Arch Dis Child. 2008;93:428-432.

6.Wolf MS, Wilson EAH, Rapp DN, et al. Literacy and learning in health care. Pediatrics. 2009;124(5 suppl):S275-S281.

7.Borzekowski DLG. Considering children and health literacy: a theoretical approach. Pediatrics. 2009;124(5 suppl):S282S288.

8.Abrams MA, Klass P, Dreyer BP. Health Literacy and Children: Introduction. Pediatrics. 2009;124(suppl 3):S262-S264. 
9.DeWalt DA, Hink A. Health Literacy and Child Health Outcomes: A Systematic Review of the Literature. Pediatrics. 2009;124(suppl 3):S265-S274.

10.Tates K, Meeuwesen L, Elbers E, Bensing J. 'I've come for his throat': roles and identities in doctor-parent-child communication. Child Care Health Dev. 2002;28(1):109-116.

11. Howells RJ, Davies HA, Silverman JD, Archer JC, Mellon AF. Assessment of doctors' consultation skills in the paediatric setting: the Paediatric Consultation Assessment Tool. Arch Dis Child. 2010;95(5):323-329.

12.Waitzkin H. Information giving in medical care. J Health Soc Behav. 1985;26(2):81-101.

13. Shapiro J. Family reactions and coping strategies in response to the physically ill or handicapped child, a review. Soc Sci Med. 1983;17(15):913-931.

14. Gould $\mathrm{H}$, Toghill PJ. Communication in medicine how should we talk about adult leukaemia to adult patients and their families? BMJ. 1981;282:210-212.

15. Wassmer E, Minnaar G, Abdel Aal N, Atkinson M, Gupta E, Yuen S, Rylance G. How do paediatricians communicate with children and parents? Acta Paediatr. 2004;93:1501-1506.

16. Pantell RH, Stewart TJ, Dias JK, Wells P, Ross AW. Physician Communication with Children and Parents. Pediatrics. 1982;70(3):396-402.

17. Merriam S. Qualitative Research in Practice: Examples for Discussion and Analysis. San Francisco: Jossey-Bass; 2002.

18. Strauss A, Corbin J. Basics of Qualitative Research: Grounded Theory Procedures and Techniques. Newbury Park, CA: Sage Publications; 1990

19. Glaser BG, Strauss AL. The Discovery of Grounded Theory: Strategies for Qualitative Research. New York: Aldine De Gruyter; 1967. 